\title{
In-situ multi-analytical study of ongoing corrosion processes on bronze artworks exposed outdoors
}

\author{
Leila Es Sebar ${ }^{1}$, Leonardo lannucci ${ }^{1}$, Caterina Gori ${ }^{2}$, Alessandro Re ${ }^{3}$, Marco Parvis ${ }^{4}$, Emma Angelini ${ }^{1}$, \\ Sabrina Grassini ${ }^{1}$
}

${ }^{1}$ Department of Applied Science and Technology, Politecnico di Torino, Italy

${ }^{2}$ Curator of the Gori Art Collection, Fattoria di Celle, Santomano, Pistoia, Italy

3 Physics Department, Università di Torino and INFN, Sezione di Torino, Italy

${ }^{4}$ Department of Electronics and Telecommunication, Politecnico di Torino, Italy

\begin{abstract}
This paper presents a long-term in-situ campaign to monitor contemporary bronze statuary exposed outdoors. The case study relates to the characterisation of three sculptures belonging to the Gori Art Collection, located in the Fattoria di Celle: 'Cavaliere' and 'Miracolo - Composizione' by Marino Marini and 'Due forme o due ombre ${ }^{\circ}{ }^{\circ}{ }^{\prime}$ by Luciano Minguzzi. The overall conservation state of the sculptures was investigated by means of a multi-analytical and non-invasive approach, involving different techniques. Three-dimensional photogrammetry was performed to fully document the artworks. The chemical and microstructural features of the corrosion patinas were then characterised through X-ray fluorescence and Raman spectroscopy. In addition, the stability and the protective effectiveness of the corrosion products were assessed by electrochemical impedance spectroscopy. Thanks to the combined use of these specific techniques, the information extracted through the different analyses could be correlated with each other and with the exposure conditions. The different corrosion products were identified as being primarily copper sulphates and phosphates, and they were correlated with the different microclimate conditions related to their location on the statues. The information gathered from the presented multi-analytical approach represents the fundamental knowledge required to develop a tailored conservation project to assure the long-lasting preservation of these artworks.
\end{abstract}

\section{Section: RESEARCH PAPER}

Keywords: In-situ measurements; Raman spectroscopy; electrochemical impedance spectroscopy; atmospheric corrosion

Citation: Leila Es Sebar, Leonardo lannucci, Caterina Gori, Alessandro Re, Marco Parvis, Emma Angelini, Sabrina Grassini, In-situ multi-analytical study of ongoing corrosion processes on bronze artworks exposed outdoors, Acta IMEKO, vol. 10, no. 1, article 32, March 2021, identifier: IMEKO-ACTA-10 (2021)-0132

Editor: Ioan Tudosa, University of Sannio, Italy

Received May 25, 2020; In final form October 20, 2020; Published March 2021

Copyright: This is an open-access article distributed under the terms of the Creative Commons Attribution 3.0 License, which permits unrestricted use, distribution, and reproduction in any medium, provided the original author and source are credited.

Corresponding author: Leila Es Sebar, e-mail: leila.essebar@polito.it

\section{INTRODUCTION}

Conservation prevents or slows the deterioration of cultural heritage by controlling the environment and the artwork's structure to maintain it in as unchanged a state as possible. According to the latest definitions, conservation includes preventive conservation, remedial conservation and restoration. All measures and actions in this field should respect the significance and the physical properties of the cultural heritage item. At the 15th Triennial Conference (New Delhi, September 2008) the ICOM-CC (International Council of Museums Committee for Conservation) defined the term 'preventive conservation' as 'all measures and actions aimed at avoiding and minimizing future deterioration or loss. They are carried out within the context or on the surroundings of an item, but more often a group of items, whatever their age and condition. These measures and actions are indirect - they do not interfere with the materials and structures of the items. They do not modify their appearance.' [1] Indeed, the deterioration and loss of our cultural heritage are inevitable processes. However, it is possible to slow these processes down and to preserve artworks for as long as possible if the right methodologies and preventive conservation projects are implemented.

When dealing with heritage metallic artefacts, particular care has to be taken because of the strong interaction between these objects and their surrounding environment. Many authors [2]-[4] have discussed the strategies and methodologies necessary to 


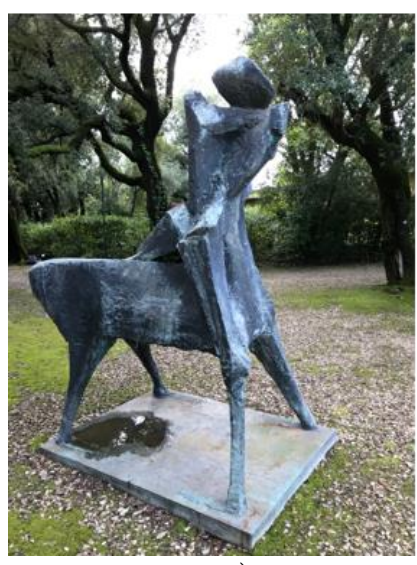

a)

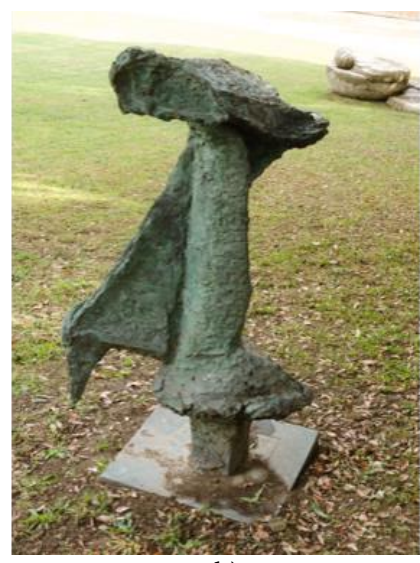

b)

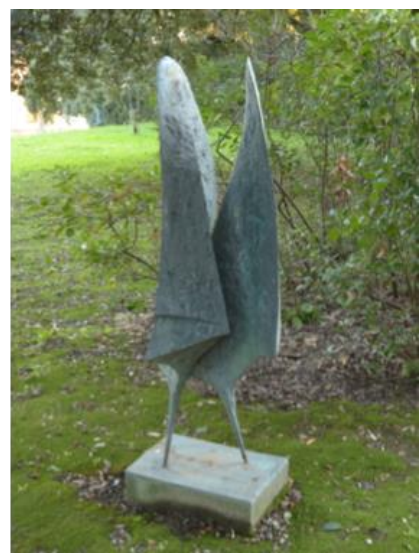

c)

Figure 1. The artworks of the Gori Art Collection under study: a) 'Cavaliere' and b) 'Miracolo - Composizione' by Marino Marini; c) 'Due forme o due ombre ${ }^{\circ} 2^{\prime}$ by Luciano Minguzzi.

investigate the degradation mechanisms and corrosion products in the cultural heritage field, as all measurements should be noninvasive and non-destructive.

In this study, phenomena and products related to the atmospheric corrosion of bronze artefacts are investigated There are many research projects with the overall aim of investigating this issue with a focus on atmospheric (rural, urban, marine, etc.) [5] and exposure conditions, appearance and morphology of the corrosion patinas by means of different analytical techniques.

This paper presents a multi-analytical approach applied to the assessment of the conservation state of artistic installations and sculptures exposed outdoors. Different and complementary analytical techniques were required to gain an overall characterisation of the artefacts and an assessment of their conservation state, together with the documentation of any change in the aesthetical appearance directly related to material degradation during the exposure time. This is a fundamental aspect of the definition of projects that assures the long-lasting preservation of artworks. The conservation of bronze artefacts exposed outdoors is influenced by the alloy composition and the chemical, microstructural and morphological features of the corrosion products formed on the metallic surface due to the interaction with the atmosphere, as well as by environmental and microclimate parameters.

Three-dimensional (3D) photogrammetry, Raman spectroscopy (RS), portable X-ray fluorescence ( $\mathrm{p}-\mathrm{XRF}$ ) and electrochemical impedance spectroscopy (EIS) were exploited for an in-situ monitoring campaign. Only by combining the information derived from all these techniques is it possible to reach a deeper understanding of the artwork's conservation state. RS and $\mathrm{p}$-XRF were exploited to identify which corrosion products were present and to characterise their chemical and microstructural features. EIS was conducted to evaluate the electrochemical stability and the protective effectiveness of the corrosion product layers. Photogrammetry allows the creation of a 3D model of an item, documenting geometrical, textural and colour features, all of which can change over time due to exposure to the outdoor atmosphere. These techniques are proven to be suitable for the cultural heritage field [6]-[14]. In this paper, the possibilities offered by portable instruments for in-situ and non-invasive measurements are presented.

The bronze sculptures under study are part of a private modern art collection, the Gori Art Collection (located in Fattoria di Celle, Pistoia, Italy). The investigated artefacts are all exposed to the same rural environment, with similar exposure conditions, and they were all cast in the same period (the second part of the $20^{\text {th }}$ century). Even if the items are of recent realisation, the information regarding the production techniques and the conservation state are not easy to find. Therefore, a monitoring campaign was initiated in 2018, which is still in progress, to assess the atmospheric corrosion phenomena affecting the artworks as a function of the time of exposure to the environment with the final aim of developing tailored preservation procedures.

In this paper, the results obtained for three sculptures are reported: 'Cavaliere' (1957-58) and 'Miracolo - Composizione' (1956-57) by the artist Marino Marini, and 'Due forme o due ombre n'2' (1969) by Luciano Minguzzi.

The paper is structured as follows. In section 2, the Gori Art Collection sculptures investigated in this study are presented together with the applied analytical methodologies. In section 3, the results obtained are reported and discussed. Finally, in section 4 , the major results are outlined and conclusions drawn.

\section{MATERIAL AND METHODS}

The monitoring campaign began in collaboration with the curators of the Gori Art Collection in November 2018, and it has mainly been devoted to the assessment of the conservation state of the bronze sculptures exposed outdoors.

The campaign began with the study of the 'Cavaliere' sculpture created by the Italian artist Marino Marini (Figure 1a). From December 2019, the artworks 'Miracolo - Composizione' by Marino Marini (Figure 1b) and 'Due forme o due ombre ${ }^{\circ}{ }^{2}$ ' by Luciano Minguzzi (Figure 1c) were included in the monitoring project, thus the preliminary results obtained so far for these two artworks are also presented.

\subsection{Artefacts - Gori Art Collection}

The bronze sculptures that are the subject of the present study belong to a private collection of modern art, the Gori Art Collection, located in Fattoria di Celle (Pistoia, Italy). The collection was founded in 1950 in Prato by the two owners, Giuliano and Pina Gori. Many artists contributed with their works, and soon, the collection became too large for the original location and the artworks had to be moved to a more suitable place. Therefore, in 1970, a new phase for the collection began, after its transfer to the Fattoria di Celle, a large estate situated in Santomato (Pistoia, Italy). The collection continued to grow, adopting a site-specific art programme in which the sculptures 
and the multi-material installations were directly connected to the surrounding parkland and landscape of the Fattoria di Celle, which has become an integral part of the collection. Currently, it is composed of 80 site-specific artworks and installations created by artists from all over the world [15].

The majority of the pieces in the collection are permanently installed in the gardens of the Fattoria di Celle, in some cases in direct contact with soil or water. The artworks are connected to the space that surrounds them, therefore no protection from the environment is present. As a consequence, there are many corrosion phenomena present, which can affect these artworks.

In this paper, only some of the bronze artworks under study will be presented, in particular, the in-situ monitoring of the 'Cavaliere' sculpture, created by the Italian artist Marino Marini. The sculpture was part of the exhibition hosted by the Fondation Maeght in Saint-Paul-de-Vence (France) in 2012 [16], [17]. Marino Marini (1901-1980) was an Italian sculptor, who developed his work through several themes: equestrian statues, the divinities, portraits and circus figures. He drew on traditions of Etruscan and Northern European sculpture in developing these themes. His aim was to develop mythical images by interpreting classical themes in light of modern concerns and techniques. The sculpture under study is part of the collection, and it is located in the villa's garden, in contact with the soil, in an area surrounded by trees and near a fountain.

The second of Marino Marini's sculptures is an object of characterisation, the 'Miracolo - Composizione', found by Biancalucia Maglione and confirmed with the Fondazione Marini of Pistoia in December 2015 [17].

The third item of study is 'Due forme o due ombre $n^{\circ} 2$ ' by Luciano Minguzzi (1911-2004), an Italian sculptor whose products ranged from a series of vigorous plastic works featuring acrobats, contortionists and children at play to concentration camps, gas chambers and other war-related themes.

All the artworks under study are placed in a similar context, on the ground and close to trees and bushes.

Even though all the artefacts are recently produced, there is a lack of information about the materials employed by the artists in their creation. Moreover, information regarding the production techniques is limited.

Different areas of the sculptures were investigated after a first visual inspection. The areas were selected on the basis of the exposure conditions and the colour of the corrosion patina. Some of the corrosion patinas under study are shown in Figure 2. As can be observed, black (g), light green (f), light blue-green $(\mathrm{a}, \mathrm{b}, \mathrm{e})$, bright dark-green (h), green (c) and blue (d) corrosion patinas are present on the sculptures' surfaces. Those indicated as a), b) and e) were detected on the bases of the sculptures, while the patinas labelled as c), d), f) and g) were mainly found on unsheltered surfaces, such as the side of the sculptures. Finally, the area indicated as $h$ ) has the aspect characteristic of patinas present on unsheltered surfaces.

Hereinafter, the analysis points on the 'Cavaliere' sculpture will be labelled as 'CAV', on 'Miracolo - Composizione' as 'MIR' and on 'Due forme o due ombre $n^{\circ} 2$ ' as 'DUE'. In addition, all measurements will be identified according to their position on the artworks: those performed on the base will be labelled as '_B', on the lateral unsheltered points as '_U' and on sheltered points as '_S'. Finally, the single measurement will be identified by adding a two-digit sequential number.

\subsection{Multi-analytical investigation}

In order to characterise the corrosion processes that are affecting the bronze sculptures, identify the corrosion products and assess the overall conservation state, an in-situ multianalytical and non-invasive approach was adopted. Indeed, the artworks cannot be moved, and techniques that require sampling are not suitable for artefacts with an artistic value.

First, a 3D photogrammetry survey was carried out to create a complete set of documentation for the artworks. The chemical and microstructural features of the corrosion patinas were then characterised by means of XRF and RS. Finally, the conservation state of the bronze sculptures was investigated using EIS in order to assess the stability and the protective capability of the corrosion patinas on the artefact's surface.

\subsubsection{Photogrammetry}

Photogrammetry is a technique that has become increasingly widespread in the cultural heritage field. Documentation is a fundamental aspect of a monitoring campaign, and thanks to this technique, it is possible to store a $3 \mathrm{D}$ model with information about the colour, geometry and texture of an artefact.

The photogrammetry measurements were performed using a NIKON D3100 camera and AF-S DX ZOOM-NIKKOR 18$55 \mathrm{~mm} \mathrm{f} / 3.5-5.6 \mathrm{G}$ ED lens. Image acquisition conditions were set before starting in order to obtain sharp and clean images. In particular, the lens focal length was fixed at $18 \mathrm{~mm}$, with an aperture of $\mathrm{f} / 6.3$, an exposure time of $1 / 125$ and an ISO sensitivity equal to 400 . The image acquisition was performed at different heights, circling around the artefact and also taking close-ups. Finally, for all the sculptures, a picture with a colour chart in view was taken to ensure accurate colour reproduction. The images were obtained and saved in RAW format. MicMac (Multi-Images Correspondances, Méthodes Automatiques de Correélation), the open-source program developed by the French National Geographic Institute (IGN), was employed [18].

The workflow described below was followed. First, the acquired images were inspected to eliminate those that did not fulfil the required quality. Next, the selected images were aligned, and the sparse cloud, dense cloud and mesh were constructed to set the medium quality level. Subsequently, the model was cut in

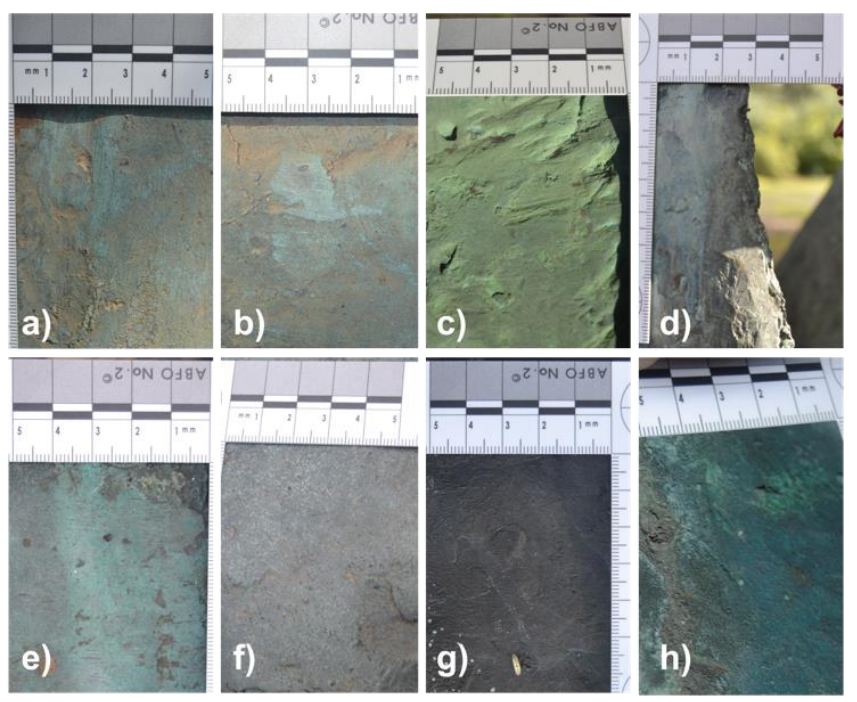

Figure 2. View of some investigated bronze surfaces. a) DUE_B 01; b) DUE_B 02; c) DUE_U 01; d) DUE_U 03; e) CAV_B 01; f) CAV_U 05; g) CAV_U 07; h) CAV_S 01 . 


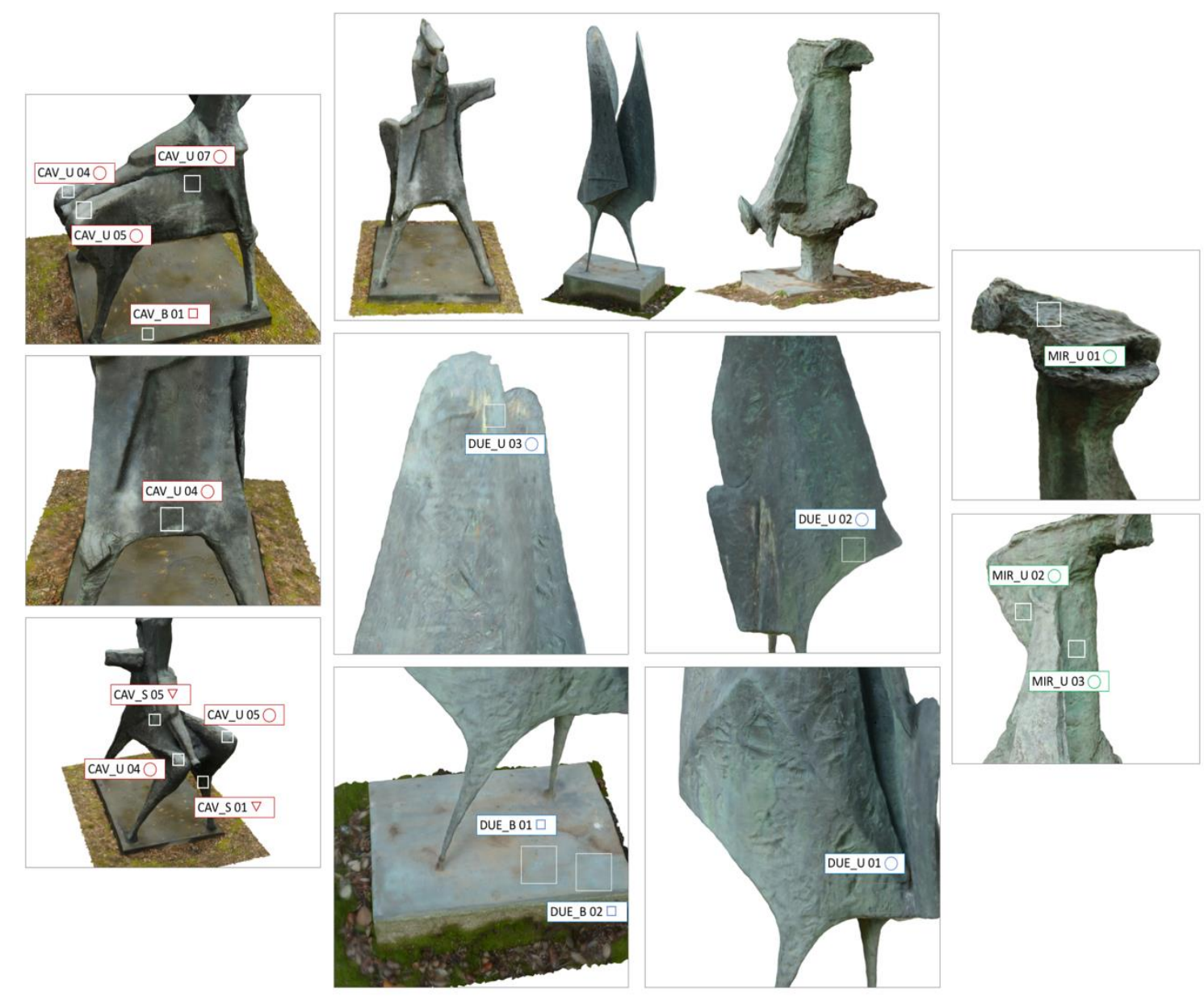

Figure 3. Views of the 3D models created for the three artworks. Some of the points of analysis are indicated.

order to contain only the region of the sculpture that was of interest, and the model was then constructed and the texture applied to the highest quality.

\subsubsection{X-ray fluorescence}

The portable X-ray fluorescence spectrometer is an important tool for the in-situ investigation of metallic artworks. Indeed, by means of XRF, it is possible to perform a completely noninvasive and non-destructive element identification on an artefact's surface.

A Bruker Tracer $5 \mathrm{i}$ analyser was employed. The instrument is equipped with a proprietary $20 \mathrm{~mm}^{2}$ silicon drift detector and a rhodium (Rh) excitation source. For the analysis, the voltage and current were set to the values of $30 \mathrm{kV}$ and $14 \mu \mathrm{A}$, respectively, and the $3 \mathrm{~mm}$ collimator was mounted.

The collected spectra were processed using the Artax Spectra (8.0.0.476) software. A Bayesian deconvolution of the collected spectra was performed after elemental interference (pile up and escape peaks) and background correction. A net counts rate for each element was then obtained.

The principal component analysis (PCA) was used with the final aim of recognising different patterns on the net counts rate and, thus, discriminating between the alloys of the different sculptures. The pre-processing of the data involved, first, a logarithmic scaling, by which the net count rate value $x$ is replaced by $\log (x)$. Then, the mean centering and variance scaling were applied; for each specific element, the mean value was subtracted and divided by the standard deviation [19].

\subsubsection{Raman spectroscopy}

In order to perform the chemical and microstructural characterisation of the corrosion products, Raman spectroscopy measurements were conducted. Specifically, the portable iRaman Plus (BWTEK) was employed. This instrument is equipped with a green excitation laser (532 nm), a spectrometer (BWS465-532S) that works in the range of 150 to $4,200 \mathrm{~cm}^{-1}$, with a resolution of $7.3 \mathrm{~cm}^{-1}$, using a CCD sensor with a cooling system. The analytical conditions were a laser power of $6 \mathrm{~mW}$, an integration time of $30 \mathrm{~s}$ and 3 repetitions in each area of analysis. The analysed surface did not undergo any cleaning procedures.

The acquired Raman spectra were processed using the PCA by means of a Python script. The pre-processing, as is commonly done for spectral analyses, involved the steps described below. First, only the region of interest of the spectrum, where peaks related to the corrosion mineralogical phases are found (between $200 \mathrm{~cm}^{-1}$ and $1,300 \mathrm{~cm}^{1}$ ), was selected. The baseline was then removed by means of asymmetric least squares smoothing. A Savitzky-Golay filter was successively applied using a window length of $15 \mathrm{~cm}^{-1}$ and fitting the original spectrum with a secondorder polynomial. A standard normal variate transformation was then carried out. Finally, the obtained spectrum was processed in order to find the principal components [20].

\subsubsection{Electrochemical impedance spectroscopy}

EIS was the selected technique for both the evaluation of the protective effectiveness of the corrosion patinas present on the 


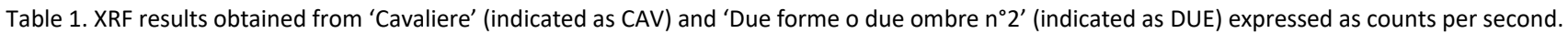

\begin{tabular}{|c|c|c|c|c|c|c|c|c|c|c|c|}
\hline & $\mathrm{Cu}$ & $\mathrm{Pb}$ & $\mathrm{Zn}$ & Sn & $\mathrm{Ca}$ & $\mathrm{Ni}$ & $S$ & Al & $\mathrm{K}$ & Si & $\mathbf{P}$ \\
\hline DUE_U 03 & 590004 & 8162 & 26142 & 170 & - & 1888 & 10 & 153 & - & - & 136 \\
\hline DUE_U 02 & 458367 & 4236 & 43790 & 183 & - & 824 & 10 & 129 & - & - & 28 \\
\hline DUE_U 01 & 589645 & 4598 & 21856 & 158 & - & 1190 & 10 & 127 & - & - & 16 \\
\hline DUE_B 02 & 506225 & 8578 & 45229 & 213 & - & 1554 & 10 & 89 & - & - & 98 \\
\hline DUE_B 01 & 539622 & 9391 & 35579 & 242 & - & 1709 & 10 & 136 & - & - & 60 \\
\hline CAV_S 10 & 515908 & 17757 & 22252 & 619 & 359 & 366 & 579 & 127 & - & 19 & 19 \\
\hline CAV_S 09 & 526733 & 20171 & 28701 & 1244 & 459 & 744 & 531 & 138 & - & 28 & 7 \\
\hline CAV_S 08 & 523469 & 12352 & 29929 & 1200 & 384 & 896 & 396 & 127 & - & 29 & 20 \\
\hline CAV_S 07 & 453529 & 13579 & 20405 & 1009 & 359 & 425 & 479 & 98 & - & 6 & 15 \\
\hline CAV_S 06 & 538036 & 9741 & 24153 & 347 & 256 & 460 & 500 & 124 & - & 13 & 36 \\
\hline CAV_U 03 & 569577 & 5159 & 23296 & 12 & 48 & 596 & 402 & 139 & 20 & 32 & 15 \\
\hline CAV_U 02 & 550258 & 5252 & 22204 & 17 & 67 & 568 & 448 & 152 & 33 & 22 & 27 \\
\hline CAV_U 01 & 377554 & 25165 & 36945 & 2655 & 938 & 1259 & 353 & 96 & 1 & 12 & 52 \\
\hline CAV_B 02 & 451979 & 28305 & 27094 & 381 & 509 & 643 & 348 & 142 & 77 & 55 & 83 \\
\hline CAV_B 01 & 335434 & 28098 & 13535 & 709 & 523 & 389 & 173 & 93 & 68 & 33 & 30 \\
\hline
\end{tabular}

bronze artefacts and for the monitoring of their stability as a function of the exposure time in relation to the aggressivity of the environment [21]-[23].

The experimental setup exploited in this study is composed of a portable electrochemical interface (Ivium-CompactStat.e 10800) and a measuring probe suitable for non-invasive measurements. The probe is a two-electrode cell, with a Pt wire as a counter electrode and the bronze artefact as the working electrode. The probe can be fixed to the metal surface by means of an adhesive closed-cell polyurethane disc and then easily removed, as described in [24], [25]. This particular configuration allows EIS measurements to be performed in situ, where the artefacts are stored, with a non-invasive approach [26].

As a consequence, it is possible to relate the information regarding the corrosion behaviour of the material exposed to the surrounding environment. The impedance measurements were performed by applying an alternating voltage in the range of 10 to $100 \mathrm{mV}$, in the frequency range of $0.01 \mathrm{~Hz}$ to $100 \mathrm{kHz}$; $\mathrm{Na}_{2} \mathrm{SO}_{4} 0.1 \mathrm{M}$ solution was employed as an electrolyte.

\section{RESULTS AND DISCUSSION}

In this section, the results obtained in the long-term monitoring campaign are presented.

\subsection{Photogrammetry}

Photogrammetry is a technology recently introduced into the cultural heritage field, and it presents the possibility of achieving many useful goals. One example is the possibility of sharing and communicating art using visual presentations, both for museum and educational purposes. Furthermore, a 3D model can be used as a support for restoration or for the creation of physical replicas. In addition, digital 3D models can be a resource for cataloguing information about the characterisation of the shape, colour and texture of artefacts and for supporting diagnostics. These last aspects are the ones stressed in this study. Indeed, photogrammetry was applied to the documentation of the conservation state of the sculpture and to store information relating to the investigated areas.

In Figure 3, the digital 3D models constructed within this monitoring project are shown. It is worth noting that the models are a photorealistic reproduction of the works of art.

An example of how 3D models can be a tool for supporting a monitoring campaign is shown in Figure 3. All the information regarding the analysed area was organised and integrated into the model itself. Therefore, it became an accessible resource, useful during the campaign, for the data processing and for sharing knowledge with curators in a more efficient way than with traditional 2D images.
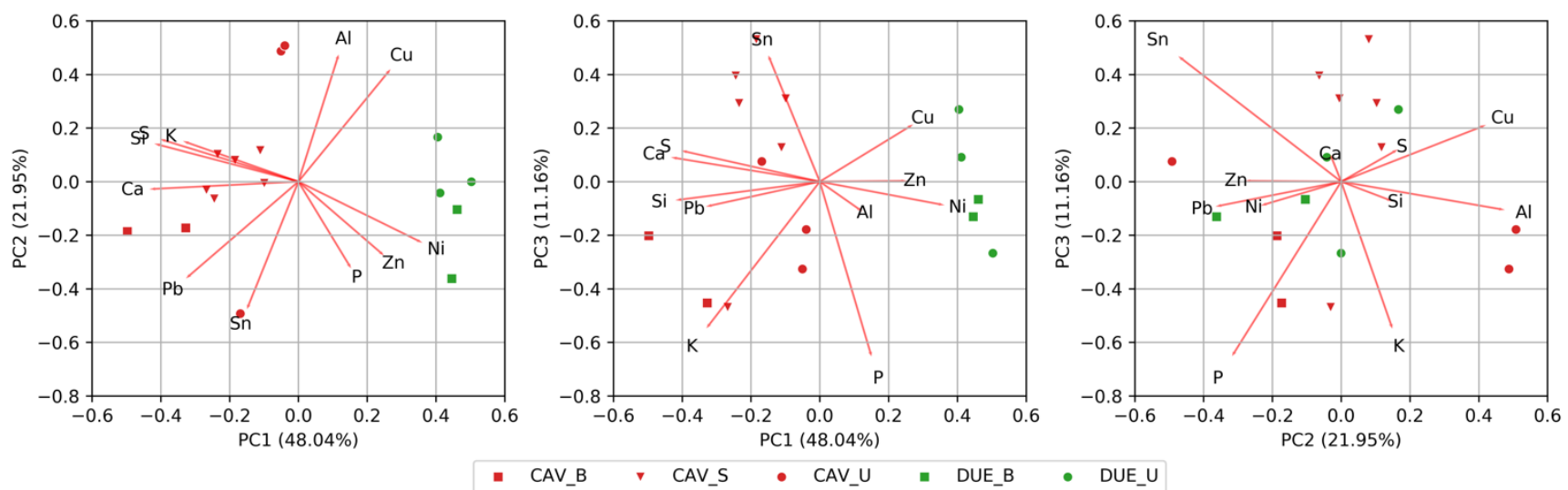

Figure 4. Score and loading plots of the first three components (PC1-PC2, PC1-PC3 and PC2-PC3) of XRF data. 

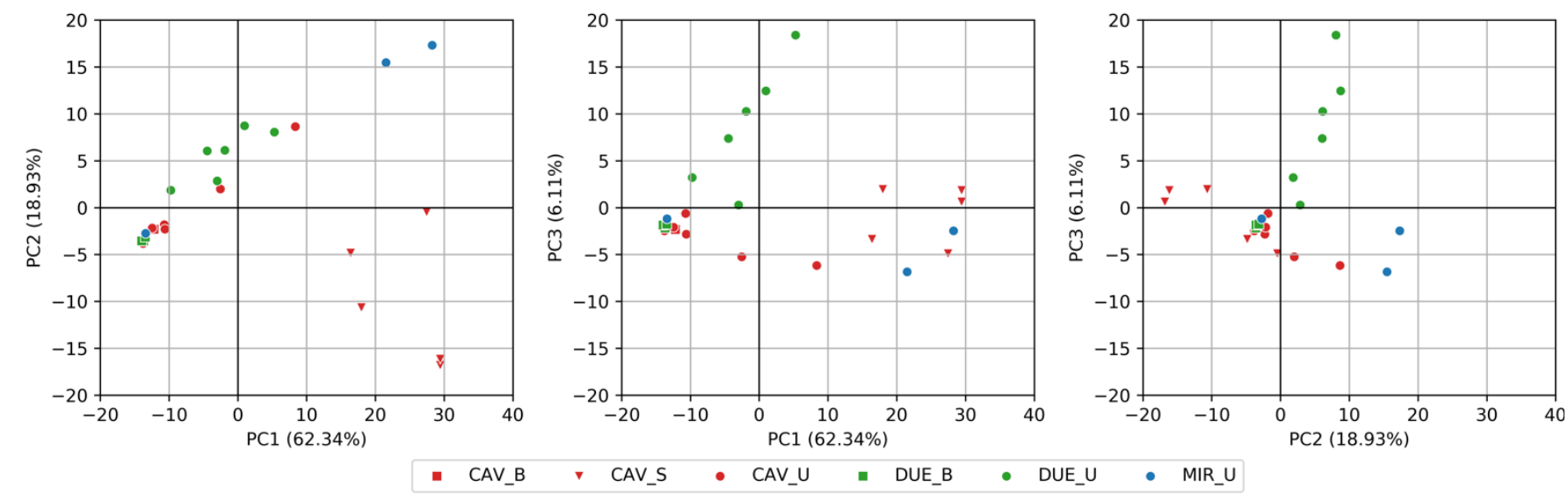

Figure 5. Score plots of the first three components (PC1-PC2, PC1-PC3 and PC2-PC3) calculated from Raman spectroscopy measurements. Percent variance captured by each PC is reported in parenthesis along each axis.

This approach can also be used to display the results of the monitoring project, as was done in [27]-[30]. In addition, the final model can be uploaded onto online platforms, such as the collection website, with engaging video sequences or as interactive models [31].

\section{2. $X R F$ results}

In order to investigate the elemental composition of the artefacts that are the subjects of this study, X-ray fluorescence spectroscopy was used. The XRF superficial element analysis is useful for investigating the composition of the corrosion products and the alloy used by the artist. XRF analyses were carried out on both the 'Cavaliere' and 'Due forme o due ombre $\mathrm{n}^{\circ} 2$ ' sculptures.

Thanks to the XRF analysis, it was possible to identify all the elements, as shown in Table 1, together with the net intensities obtained through Bayesian deconvolution. Since it was not possible to use a suitable calibration due to the presence of the

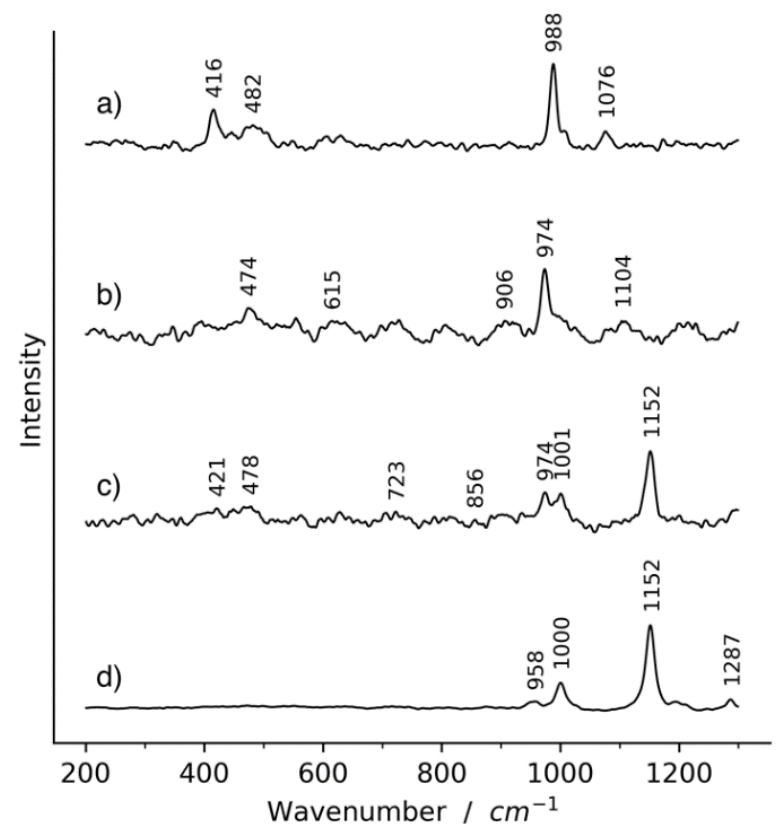

Figure 6. Representative Raman spectra collected. a) CAV_S 03, antlerite; b) MIR_U 03 brochantite, pseudomalachite; c) CAV_U 03 brochantite, kipushite and silicates; d) DUE_B 01 silicates. corrosion patina, the analysis performed had to be semiquantitative. Therefore, the reported quantities should be interpreted as a relative concentration of elements for each investigated area.

The obtained elements list defines the material of the sculptures as bronze composed mainly of $\mathrm{Cu}, \mathrm{Sn}, \mathrm{Pb}$ and $\mathrm{Zn}$, in accordance with modern bronze composition [32]. The presence of $\mathrm{Ca}, \mathrm{Si}, \mathrm{K}, \mathrm{P}$ and $\mathrm{Al}$ can be attributed to soil or environmental contamination.

In order to interpret the large amount of collected data, a PCA analysis was performed. The results obtained after the PCA data processing (Section 2.2.2) of both sculptures are summarised in Figure 4 as biplots, with both the loadings and the scores for the two selected components (PC1-PC2, PC1-PC3, PC2-PC3) shown in parallel. Data are reported with different colours and markers based on the sculpture and on the analysed area; red was assigned to the 'Cavaliere' work of art, while green to 'Due forme o due ombre $n^{\circ} 2$ '. Different markers were used to discriminate between the areas where the analysis was performed, as described in the previous section.

As is evident from the PC1-PC2 plot (Figure 4), data are divided into two main clusters, one for each sculpture. This behaviour is mainly due to the PC1 values, which were positive for the points related to the 'Due forme o due ombre $\mathrm{n}^{\circ} 2$ ' and negative for the other sculpture. This evidence can be related to a major difference in the alloy composition, represented by the nickel and zinc content.

Moreover, looking at the PC1-PC3 plot, it is possible to see that the measurements relating to the 'Cavaliere' base (CAV_B) are in a separate cluster from the others, suggesting that the base and the sculpture are made of two different alloys. Indeed, from a further examination of the 'Cavaliere' score points in the PC2PC3 plot, it is possible to observe that the points of the sculpture base are separated from the others and that they present $\mathrm{a} \mathrm{Pb}$ and $\mathrm{P}$ enrichment (the latter presumably due to soil contamination).

\subsection{Raman spectroscopy}

The identification of the Raman spectra was carried out taking advantage of the information derived from the XRF spectroscopy and by comparison with references from the literature [33]. From a visual inspection of the collected spectra, it was possible to identify some recurring patterns typical of copper corrosion products. Given the fact that the surfaces were not cleaned before the analysis, the spectra presented noisy 

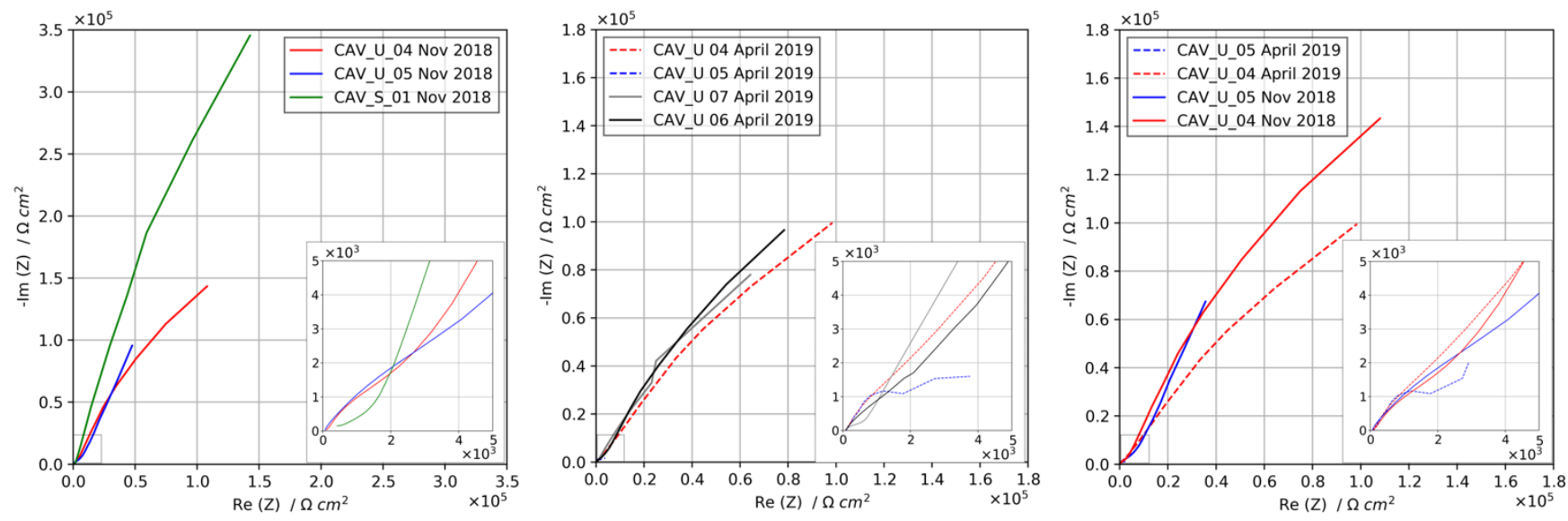

Figure 7. EIS Nyquist plots recorded for the 'Cavaliere' sculpture.

signals (due to fluorescence) and many minor peaks, which are not always easy to identify. Moreover, the monitoring campaign resulted in the collection of a large number of spectra. Therefore, PCA, an unsupervised multivariate analysis, was applied in order to identify the main patterns present in the spectra.

The obtained scores of the three principal components are plotted in Figure 5. Data are shown with markers of different shapes and colours; different colours were assigned to each sculpture (blue for 'Miracolo - Composizione', red for 'Cavaliere' and green for 'Due forme o due ombre $\mathrm{n}^{\circ} 2$ '), while different shapes were chosen to represent the category of the investigated area, as done previously.

From the PC1-PC2 plot in Figure 5, it can be seen that the measurements are grouped in four main clusters. The first group is composed of the 'CAV_S' points, with positive PC1 values and negative PC2 values. The 'Miracolo - Composizione' measurements belong to a separate cluster, with positive PC1 and PC2 values. There is a well-defined group composed of points with negative PC1 and PC2 values, while the remaining points can be grouped as having a positive PC2 value.

In Figure 6, a representative spectrum is reported for each of the four groups. The first group (Figure 6a, CAV_S) was identified on the basis of the four major bands at $416 \mathrm{~cm}^{-1}, 482$ $\mathrm{cm}^{1}, 988 \mathrm{~cm}^{1}$ and $1,076 \mathrm{~cm}^{-1}$, which are associated with antlerite, a basic copper sulphate $\left(\mathrm{Cu}_{3}(\mathrm{OH})_{4} \mathrm{SO}_{4}\right)$. With regard to the second (Figure 6b, MIR_U 03), the major peak assignments, 474 $\mathrm{cm}^{-1}, 615 \mathrm{~cm}^{-1}, 906 \mathrm{~cm}^{-1}, 974 \mathrm{~cm}^{-1}$ and $1,104 \mathrm{~cm}^{-1}$, allow its identification as brochantite $\left(\mathrm{Cu}_{4} \mathrm{SO}_{4}(\mathrm{OH})_{6}\right)$. Moreover, some of the peaks $\left(974 \mathrm{~cm}^{-1}\right.$ and the shoulder at $997 \mathrm{~cm}^{-1}, 800 \mathrm{~cm}^{-1}$ and $605 \mathrm{~cm}^{-1}$ ) could be related to the presence of copper phosphates, such as pseudomalachite. The third typology (Figure 6c, CAV_U 03) was identified as a mixture of different mineralogical phases. The bands at $421 \mathrm{~cm}^{-1}, 478 \mathrm{~cm}^{-1}$ and $974 \mathrm{~cm}^{-1}$ can be assigned to brochantite; the $478 \mathrm{~cm}^{-1}, 723 \mathrm{~cm}^{-1}, 856 \mathrm{~cm}^{-1}, 974 \mathrm{~cm}^{-1}$ and $1,001 \mathrm{~cm}^{-1}$ vibration bands are typical of hydroxy-phosphates and can be assigned to Kipushite (RRUFF ID-R060826 [34]), while $1,152 \mathrm{~cm}^{-1}$ is characteristic of silicate vibration modes [35]. Finally, the fourth spectrum (Figure 6d, DUE_B 01) vibration modes, $958 \mathrm{~cm}^{-1}, 1,000 \mathrm{~cm}^{-1}, 1,152 \mathrm{~cm}^{-1}$ and $1,287 \mathrm{~cm}^{-1}$, are typical of silicates [35].

Given these results, it is possible to confirm the presence of different corrosion mineralogical phases, such as copper sulphates, i.e. brochantite and antlerite, and copper phosphates, i.e. kipushite and pseudomalachite (the presence of phosphorus was also detected by XRF measurements). The presence of silicates was observed, mainly as a contaminant present on the sculpture surfaces. Furthermore, it is possible to correlate the corrosion products with their location and exposure conditions, in accordance with the model proposed by [35]-[38]. Indeed, in all the analysed areas located on the side of the sculpture, i.e. on rain-exposed surfaces, the presence of brochantite was evident. This kind of soluble compound can be leached by rains, thus creating a cyclic corrosion mechanism linked to the frequency with which the surface is exposed to rain. A phase such as brochantite can be more stable in sheltered areas, but only in the 4-6 $\mathrm{pH}$ range. If the acidity of the water film present on the surface increases and the $\mathrm{pH}$ is lowered to values below 4 [33],[37], the precipitation of antlerite is observed. In this study, antlerite was identified in the areas referred to as '_S', which relates to the sculptures' sheltered surfaces, where there is a low water evaporation rate.

\subsection{Electrochemical impedance spectroscopy}

EIS measurements were performed in two different campaigns, the first in November 2018 and the second in April 2019. EIS is a powerful tool that allows researchers to investigate the corrosion mechanisms affecting metal surfaces and the stability of the superficial oxide and corrosion product layers in a specific environment. Thus, impedance measurements were performed in order to correlate the chemical composition and morphology of the corrosion product layers with their electrochemical behaviour and to assess the protective effectiveness of the different corrosion patinas.

The results are summarised in Figure 7 as Nyquist plots. Looking at the EIS spectra acquired during the November 2018 campaign, it is possible to observe higher impedance values for point CAV_S01, which was in a sheltered position, compared to points CAV_U04 and CAV_U05, which were in an unsheltered position on the statue. The different electrochemical behaviours can be correlated with the different thicknesses of the patinas, depending on their exposure conditions. Indeed, corrosion products present on unsheltered surfaces are more likely to be washed away by rain, reducing their thickness. It is worth noting that by also using Raman spectroscopy, it was possible to identify two different behaviours on the basis of the location. As discussed in the previous section, RS experimental findings highlighted the presence of antlerite only in correspondence to sheltered positions, while brochantite is the main corrosion product detected in the unsheltered areas. Thus, correlating the information obtained using these two techniques allows the ongoing corrosion mechanism to be explained. Patina 
dissolution in pristine rain is more detrimental in unsheltered areas, where brochantite is present, and leads to a decrease in thickness and change in the degree of porosity. Therefore, in these rain-exposed areas, lower impedance values indicate a lower protective effectiveness of the corrosion patina. However, sheltered areas where antlerite is present exhibit higher impedance values because patina dissolution by rain is less effective, and its thickness is thus higher.

The high heterogeneity of the corrosion patinas was further highlighted in the April 2019 campaign. Points CAV_U04, CAV_U06 and CAV_U07 exhibited similar impedance spectra, reaching impedance modulus values in the order of $10^{5} \mathrm{ohm} \cdot \mathrm{cm}^{2}$ At the same time, point CAV_U05, which demonstrated a behaviour similar to CAV_U04 in the previous campaign, exhibited an impedance modulus more than one order of magnitude lower, confirming the preferential dissolution of brochantite in some positions.

Despite the presence of different behaviours, it is possible to conclude that in all the investigated points, the patina exhibited a good protective effectiveness for the underlying bronze substrate. The relationship between the different positions and the corresponding impedance spectrum should be further investigated in order to reach a deeper understanding of the corrosion behaviour of the patinas grown on the different points and the effect of exposure to environmental conditions.

\section{CONCLUSIONS}

The in-situ multi-analytical and non-invasive approach presented in this paper has proven to be a very interesting and effective methodology for the conservation state assessment of artefacts. This approach could be applied to different case studies, related to multi-material artefacts, allowing a continuous monitoring and documentation of the conservation state of the artefacts. Moreover, the importance of the use of portable instruments lies in the possibility of conducting the measurements in situ, thus avoiding any sampling and being able to assess the degradation of the material directly in contact with the environment to which the artwork is exposed.

The combination of techniques such as photogrammetry, Raman spectroscopy, X-ray fluorescence spectroscopy and electrochemical impedance spectroscopy can be used to provide information regarding the overall conservation state of an artefact. Indeed, it allowed the identification of which corrosion products were present and the characterisation of their chemical and microstructural features, together with their electrochemical stability and their correlation with exposure conditions and the surrounding environment. Moreover, with this approach, it is possible to document all the analysis performed on the artworks and to integrate this information into a virtual 3D model, which can be stored and shared with curators and conservators.

In addition, it was possible to identify copper sulphates as brochantite and antlerite and copper phosphate as kipushite and pseudomalachite. Furthermore, the corrosion products detected were also correlated with their location on the sculptures and with their exposure conditions, and the difference between the sheltered and unsheltered surfaces was analysed.

The information collected through the multi-analytical monitoring campaign presented in this paper is essential for establishing tailored preventive conservation strategies. Moreover, the identification of the corrosion products present can help to identify if conservation treatments, such as cleaning, passivation or coating, are necessary.

\section{ACKNOWLEDGEMENT}

The Authors would like to acknowledge Dr. Giuliano Gori, owner of the Gori Art Collection, for allowing the present investigation in the Fattoria di Celle and for the useful discussions and continuous collaboration.

\section{REFERENCES}

[1] ICOM-CC, Terminology to characterize the conservation of tangible cultural heritage. Online [Accessed 12 March 2021] www.icom-cc.org/242/about/terminology-for-conservation

[2] L. Robbiola, J. M. Blengino, C. Fiaud, Morphology and mechanisms of formation of natural patinas on archaeological CuSn alloys, Corrosion Science 40 (1998) pp. 2083-2111.

DOI: $10.1016 /$ S0010-938X(98)00096-1

[3] F. Gallese, G. Laguzzi, L. Luvidi, V. Ferrari, S. Takacs, G. Venturi Pagani Cesa, Comparative investigation into the corrosion of different bronze alloys suitable for outdoor sculptures, Corrosion Science Vol. 50 Issue 4, April 2008, pp. 954-961. DOI: $\underline{10.1016 / \text { i.corsci.2007.11.015 }}$

[4] T. E. Graedel, K. Nassau, J. P. Franey, Copper patinas formed in the atmosphere-I. Introduction, Corrosion Science 27 (1987) pp. 639-657.

DOI: $\underline{10.1016 / 0010-938 X(87) 90047-3}$

[5] V. Hayez, V. Costa, J. Guillaume, H. Terryn, A. Hubin, Micro Raman spectroscopy used for the study of corrosion products on copper alloys: study of the chemical composition of artificial patinas used for restoration purposes, Analyst 130 (2005) pp. 55055.

DOI: $\underline{10.1039 / B 419080 G}$

[6] G. Buccolieri, A. Buccolieri, P. Donati, M. Marabelli, A. Castellano, Nuclear instruments and methods in physics research $B$ portable EDXRF investigation of the patinas on the Riace Bronzes, Nuclear Instruments and Methods in Physics Research Section B: Beam Interactions with Materials and Atoms 343 (2015) pp. 101-109.

DOI: $10.1016 /$ j.nimb.2014.11.064

[7] E. Couture-Rigert, P.J. Sirois, E.A. Moffatt, An investigation into the cause of corrosion on indoor bronze sculpture, Studies in Conservation 57 (2012) pp. 142-163.

DOI: $10.1179 / 2047058412$ Y.0000000004

[8] E. Angelini, D. Assante, S. Grassini, M. Parvis, EIS measurements for the assessment of the conservation state of metallic works of art, International Journal of Circuits, Systems and Signal Processing 8 (2014) pp. 240-245.

[9] E. Angelini, C. E. Arroyave Posada, E. Di Francia, S. Grassini, L. Iannucci, L. Lombardo, M. Parvis, Indoor and outdoor atmospheric corrosion monitoring of cultural heritage assets, La Metallurgia Italiana 4 (2018) pp. 34-41.

[10] E. Angelini, S. Grassini, M. Parvis, F. Zucchi, Corrosion prediction of metallic cultural heritage by EIS, Corrosion Science and Technology 18 (2019) pp. 121-128. DOI: $10.14773 /$ cst.2019.18.4.121

[11] C. Price, D. Hallam, G. Heath, D. Creagh, J. Ashton, An electrochemical study of waxes for bronze sculpture, Metal 95: Proceedings of the international conference on metals conservation, Semur-en-Auxois, France, 25-28 September 1995, pp. 233-241.

[12] M. C. Leuzzi, M. Crippa, G. A. Costa, Application of nondestructive techniques. The Madonna Del Latte case study, ACTA IMEKO 7 (2018) 3, p. 52-56. DOI: $10.21014 /$ acta imeko.v7i3.587

[13] T. de Caro, Corrosion products of Cu-based coins from the River Tiber (Rome) analysed by micro-Raman spectroscopy, 2018 Metrology for Archaeology and Cultural Heritage (MetroArchaeo), Cassino, Italy, 22-24 October 2018, pp. 357-361. DOI: $10.1109 /$ MetroArchaeo43810.2018.9089770

[14] P. Santos, M. Ritz, C. Fuhrmann, D. Fellner, 3D mass digitization: a milestone for archeological documentation, Virtual Archaeology 
Review 8 (2017), 11 pp.

DOI: $10.4995 /$ var. 2017.6321

[15] Collezione Gori, Cenni Storici. Online [Accessed 12 March 2021] www.goricoll.it

[16] L. Hegyi, O. Kaeppelin, M. Mcphail, Arcadia in Celle. L'Art pour la Nature, la Nature pour l'Art, Maeght Fondation, Saint Paul-deVence, 2012, ISBN 102900923549.

[17] M. Marini, G. Carandente, Catalogo Ragionato Della Scultura, Skira, Milano,1998, ISBN 10138881183900.

[18] E. Rupnik, M. Daakir, M. Pierrot Deseilligny, MicMac - a free, open-source solution for photogrammetry, Open Geospatial Data, Software and Standards 2 (2017), 9 pp. DOI: $10.1186 / \mathrm{s} 40965-017-0027-2$

[19] P. Gemperline, Practical Guide to Chemometrics, CRC Press, Boca Raton, 2006, ISBN 1-57444-783-1.

[20] J. N. Miller, J. C. Miller, Statistics and Chemometrics for Analytical Chemistry, Pearson, Harlow, 2010, ISBN 978-0-273-73042-2.

[21] E. Cano, D. Lafuente, D. M. Bastidas, Use of EIS for the evaluation of the protective properties of coatings for metallic cultural heritage: a review, Journal of Solid State Electrochemistry 14 (2010) pp. 381-391. DOI: $\underline{10.1007 / \mathrm{s} 10008-009-0902-6}$.

[22] Y.-T. Kuo, C.-Y. Lee, Y.-L. Lee, Compact coating impedance detector for fast evaluation of coating degradation, Measurement 124 (2018) pp. 303-308. DOI: $10.1016 / \mathrm{i}$.measurement.2018.04.041.

[23] O. Baradel, R. Nuttall, Comparison of corrosion rates evaluated from polarisation resistance and electrochemical impedance spectroscopy measurements, IEEE Colloquium on Electrochemical Measurement, London, UK, 17 March 1994, pp. 8/1-810.

[24] L. Es Sebar, A. Re, M. Parvis, E. Angelini, S. Grassini, A long-term corrosion investigation of bronze sculptures exposed outdoor, Proc. of 2019 IMEKO TC4 International Conference on Metrology for Archaeology and Cultural Heritage, MetroArchaeo 2019, Firenze, Italy, 4-6 December 2019, pp. 549-553. Online [Accessed 19 March 2021] https://www.imeko.org/publications/tc4-Archaeo2019/IMEKO-TC4-METROARCHAEO-2019-107.pdf

[25] L. Es Sebar, M. Parvis, S. Grassini, E. Angelini, Monitoraggio dello stato di conservazione delle opere d'arte della Collezione Gori, La Metallurgia Italiana 4 (2020), pp. 73-77.

[26] S. Grassini, S. Corbellini, M. Parvis, E. Angelini, F. Zucchi, A simple Arduino-based EIS system for in situ corrosion monitoring of metallic works of art, Measurement 114 (2018), pp. 508-514. DOI: $10.1016 / \mathrm{i}$. measurement.2016.07.014

[27] F. I. Apollonio, V. Basilissi, G. Bitelli, M. Callieri, D. Catalano, M. Dellepiane, M. Gaiani, F. Ponchio, F. Rizzo, A. R. Rubino, R. Scopigno, Il restauro della Fontana del Nettuno a Bologna. Un sistema 3D web per la documentazione e la gestione dei dati, Archeomatica 8 (2017), pp. 30-34.

[28] A. Angelini, D. Portarena, Advice for archaeological survey with recent technologies, ACTA IMEKO 7 (2018) 3, pp. 42-51.
DOI: $10.21014 /$ acta imeko.v7i3.586

[29] S. Bracci, F. Falletti, M. Matteini, R. Scopigno, Exploring David: diagnostic tests and state of conservation, Giunti Editore, Florence (Italy), 2004, ISBN 88-09-03325-6.

[30] M. Dellepiane, M. Callieri, M. Corsini, R. Scopigno, Using digital 3D models for study and restoration of cultural heritage artifacts, in: Digital Imaging for Cultural Heritage Preservation: Analysis, Restoration, and Reconstruction of Ancient Artworks, CRC Press, Taylor \& Francis Group, United States, 2017, pp. 39-68, ISBN 9781138073791.

[31] E. Bonacini, D. Tanasi, P. Trapani, Digital heritage dissemination and the participatory storytelling project \#iziTRAVELSicilia: the case of the Archaeological Museum of Syracuse (Italy), ACTA IMEKO 7 (2018) 3, pp. 31-41.

DOI: $10.21014 /$ acta imeko.v7i3.584

[32] S. Bracci, A. Cagnini, M.P. Colombini, O.A. Cuzman, F. Fratini, M. Galeotti, D. Magrini, R. Manganelli del Fà, S. Porcinai, S. Rescic, C. Riminesi, B. Salvadori, A. Santagostino Barbone, P. Tiano, A multi-analytical approach to monitor three outdoor contemporary artworks at the Gori Collection (Fattoria di Celle, Santomato, Pistoia, Italy), Microchemical Journal 124 (2016), pp. 878-888. DOI: $10.1016 /$ i.microc. 2015.07 .008

[33] R. L. Frost, Raman spectroscopy of selected copper minerals of significance in corrosion, Spectrochimica Acta Part A: Molecular and Biomolecular Spectroscopy 59 (2003), pp. 1195-1204. DOI: $10.1016 /$ S1386-1425(02)00315-3

[34] B. Lafuente, R. T. Downs, H. Yang, N. Stone, The power of databases: the RRUFF project, In: Highlights in Mineralogical Crystallography, De Gruyter (O), 2015, pp. 1-30, ISBN 9783110417104. DOI: $10.1515 / 9783110417104-003$

[35] E. Smith, G. Dent, Modern Raman Spectroscopy—a Practical Approach, John Wiley and Sons, Chichester, 2005, ISBN 9781119440550.

[36] Robbiola, L., Fiaud, C., S. Pennec, New model of out-door bronze corrosion and its implications for conservation, In: ICOM Committee for Conservation tenth triennial meeting, 2, (1993), pp.796-802. Online [Accessed 12 March 2021] https://hal.archives-ouvertes.fr/hal-00975704

[37] L. Robbiola, L. P. Hurtel, New contribution to the study of corrosion mechanisms of outdoor bronzes. Characterization of the corroding surfaces of Rodin's bronzes, Memoires et Etudes Scientifiques de la Revue de Metallurgie 88 (1991), pp. 809-823. Online [Accessed 12 March 2021] https://hal.archives-ouvertes.fr/hal-00538986

[38] V. Hayez, J. Guillaume, A. Hubin, H. Terryn, Micro-Raman spectroscopy for the study of corrosion products on copper alloys: setting up of a reference database and studying works of art, Journal of Raman Spectroscopy 35 (2004), pp. 732-738. DOI: $10.1002 /$ irs.1194 